\title{
Relation between fetal flow patterns, coarctation of the aorta, and pulmonary blood flow
}

\author{
Elliot A. Shinebourne and A. M. Elseed \\ From the Department of Paediatrics, Brompton Hospital, National Heart and Chest Hospitals, London
}

Intracardiac anomalies cause disturbances in fetal flow patterns which in turn influence dimensions of the great vessels. At birth the aortic isthmus, which receives 25 per cent of the combined fetal ventricular output, is normally 25 to 30 per cent narrower than the descending aorta. A shelf-like indentation of the posterior aortic wall opposite the ductus characterizes the junction of the isthmus with descending aorta. In tetralogy of Fallot, pulmonary atresia, and tricuspid atresia, when pulmonary blood flow is reduced from birth, the main pulmonary artery is decreased and ascending aorta increased in size. Conversely in intracardiac anomalies where blood is diverted awvay from the aorta to the pulmonary artery, isthmal narrowing or the posterior indentation may be exaggerated.

Analysis of 162 patients with coarctation of the aorta showed 83 with an intracardiac anomaly resulting in increased pulmonary blood flow and $2 I$ with left-sided lesions present from birth. In contrast no patients with coarctation were found with diminished pulmonary flow or right-sided obstructive lesions. From this evidence the hypothesis is developed that coarctation is prevented when flow in the main pulmonary artery is reduced in the fetus.

The association of coarctation with left-sided obstructive lesions such as mitral and aortic stenosis is well documented (Tawes et al., 1969; Becker, Becker, and Edwards, 1970). Absence of coarctation with tetralogy of Fallot was also noted in these series but no explanation given. In reviewing 650 necropsies of aortic or pulmonary valve obstruction in children, Hutchins (1971) found no case of coarctation with right ventricular outflow tract obstruction, but of 173 patients with left-sided obstruction, 60 per cent had coarctation. As chance seemed an unlikely cause for these associations, we thought it appropriate to examine the intracardiac anomalies in patients with coarctation seen at our hospital in the hope that the pattern of anomalies might shed light on the pathogenesis of coarctation. Rudolph, Heymann, and Spitznas (1972) recently proposed a haemodynamic explanation for coarctation based on fetal flow patterns and the analysis presented here is considered from this viewpoint.

\section{Patients and methods}

Data from cardiac catheterization, angiocardiography, surgical findings, or necropsy reports were adequate in

Received 20 August 1973. establishing the complete intracardiac diagnosis in 162 patients with coarctation. The ages ranged from I day to 14 years and represent all patients under the age of 15 years with a proven diagnosis of coarctation of the aorta seen at the Brompton Hospital between January 1967 and December 1972.

Of 162 patients, $6 \mathrm{I}$ had isolated juxtaductal coarctation (group A) with no associated intracardiac anomaly, though in 2 an aberrant right subclavian artery was present. The remaining Ior patients all had at least one intracardiac abnormality as shown in the Table. The male:female ratio was $3: 1$ in those with isolated coarctation, but $I \cdot 3: I$ in the remainder, the ratio in the whole series being $r \cdot 7: I$.

Analysis of the physiological disturbance in those patients with an associated intracardiac anomaly showed 6I with a dominant left-to-right shunt (group B). In this group shunts principally occurred through a persistent ductus or ventricular septal defect.

Twenty-two patients (group C) had either d-transposition of the great vessels (d-TGA) or a common mixing situation at ventricular or atrial level. At cardiac catheterization an increased pulmonary blood flow was found in all group $C$ cases as adjudged by a pulmonary:systemic flow ratio $>$ I. In those cases where this calculation could not be made, the criterion was taken as plethora on the plain chest $x$-ray.

The 17 patients in group D had no intracardiac shunts but left-sided abnormalities, namely mitral or aortic 
valve disease or endocardial fibroelastosis. The remaining patient in group $D$ had hypoplastic right and left pulmonary arteries with a normal main pulmonary artery (? peripheral pulmonary stenosis due to rubella).

During the same 6-year period 2 II patients with tetralogy of Fallot were seen at the Brompton Hospital. No case of coarctation was found among this group, nor among 14 patients with pulmonary atresia and intact interventricular septum, 34 with pulmonary atresia and ventricular septal defect, and 53 with tricuspid atresia and normally related great vessels. In all this group there was diminished pulmonary blood flow. Coarctation was also not found with right ventricular outflow tract obstruction without a right-to-left shunt ( 323 cases in 6 years). Truncus arteriosus is another major anomaly which was not found with coarctation, there being no examples of coarctation among $3 \mathrm{I}$ patients.

\section{Terminology of coarctation}

The concepts of pre- and postductal coarctation or infantile and adult types of coarctation are unhelpful. The former inaccurately describes the anatomy and the latter implies differences in age of presentation, an unsuitable criterion for defining a developmental defect when the adult type may present in the first month of life! In this report, therefore, the terms juxtaductal coarctation (Rudolph et al., 1972) and abnormal isthmal narrowing will be used to describe the obstruction to aortic flow. The former is a localized constriction of the aorta situated directly opposite the junction of ductus arteriosus with descending aorta. The anatomy of the obstruction is well known but has been particularly well described by Hutchins (I97I) who showed that invariably there is an infolding of the aortic wall opposite the ductus. He was unable to demonstrate abnormal tissue and found the obstruction discontinuous with the ductus in all his cases. Aortic obstruction caused by exaggerated isthmal narrowing alone, true preductal coarctation with no juxtaductal obstruction, was always associated in our series with major intracardiac defects. It must be appreciated, however, that it is possible for isthmal narrowing and juxtaductal coarctation to coexist.

\section{Pathogenesis of coarctation}

Before advancing an explanation for the absence of coarctation in conditions such as tetralogy of Fallot or pulmonary atresia where there is diminished pulmonary blood flow, comments on the pathogenesis of coarctation are pertinent.

The haemodynamic explanation offered by Rudolph et al. (1972) for juxtaductal coarctation is that it represents an exaggeration of the normal aortic anatomy in the newborn. The neonatal aorta is characterized by a disparity in cross-sectional area between the aortic isthmus, the segment of aorta between left subclavian artery and ductus arteriosus, and the descending aorta (Patten, 1930; Sinha et al., 1969; McNamara, 1971; Shinebourne, 1974).

Fig. I shows the appearances of the aorta in a neonate of 2 days. The ductus has not yet closed

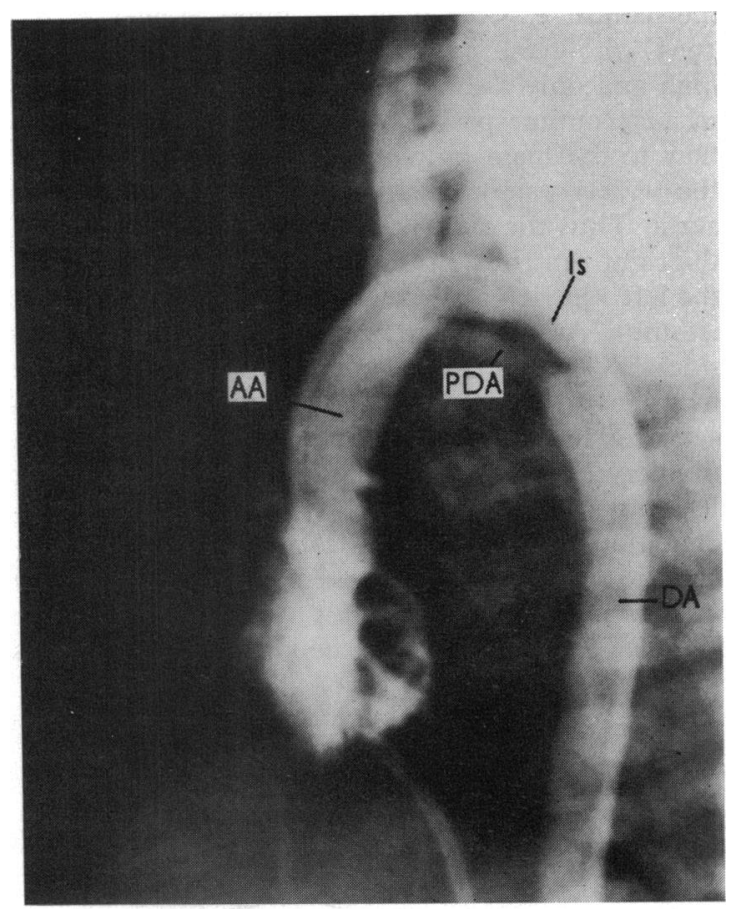

FIG. I Angiogram to show left ventricle, aorta, and small persistent ductus arteriosus in a neonate of 2 days. The ductus (PDA) has partially constricted postnatally. The aortic isthmus (IS) is shown to be narrower than the ascending $(A A)$ or descending $\operatorname{aorta}(D A)$.

completely and contrast passes retrogradely from the aorta via the ductus to the pulmonary artery. This appearance is sometimes mistakenly referred to as tubular coarctation of the aorta, but it must be stressed that this is the normal appearance in the neonate. The haemodynamic explanation for this state of affairs is derived from studies on fetal lambs (Dawes, Mott, and Widdicombe, I954; Rudolph and Heymann, 1967) and the previable human fetus (Rudolph et al., 197I) where dimensions of the great vessels appear to reflect flow through them in utero. Fig. 2 shows the proportion of the combined fetal ventricular output that passes to aorta 
and pulmonary artery. Each ventricle ejects approximately 50 per cent of the combined output to its respective great vessel.

As flow passes from ascending aorta to innominate, left common carotid, and left subclavian arteries, so aortic dimensions decrease and as a result the isthmus is 30 per cent narrower than the ascending aorta. Because of the low arterial $\mathrm{Po}_{2}$ (Cook et al., 1963; Cassin et al., 1964) and lack of mechanical expansion of the lungs (Lauer et al., 1965) the fetal pulmonary vascular resistance is high and only a small proportion of the right ventricular output passes to the lungs. Most of the flow to the main pulmonary artery passes through the widely patent ductus arteriosus to descending aorta. Thus the latter receives both the majority of the right ventricular output together with flow from the left ventricle that has passed through the aortic isthmus. As a result the descending aorta is considerably wider than the aortic isthmus and the junction of isthmus and descending aorta is characterized in the normal neonate by an indentation on the posterior wall of the aorta opposite the ductus. It is an exaggeration of this normal posterior indentation that results in isolated juxtaductal coarctation; a situation demonstrated angiographically in Fig. 3.

The other type of obstruction to aortic flow is

NORMAL NEONATAL AORTA

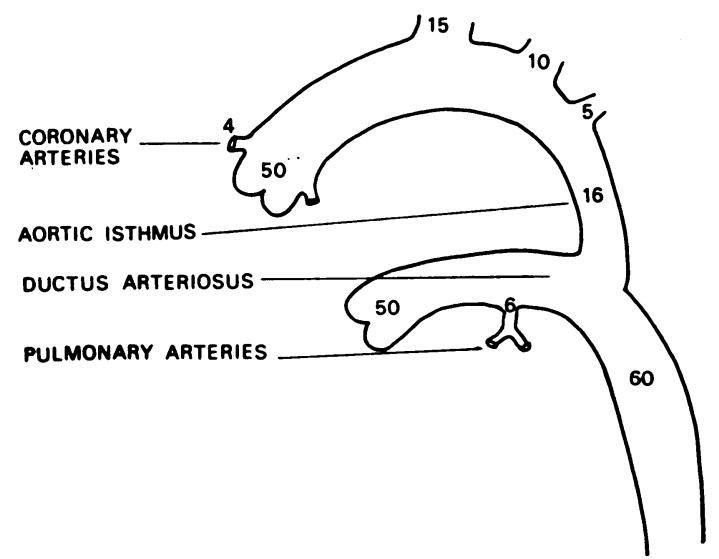

FIG. 2 Diagram to show the proportion of the combined fetal ventricular output that passes to aorta and pulmonary artery in the normal neonate at birth before closure of the ductus. The numerals indicate percentage flow traversing the vessels, and the latter are drawn to indicate their approximate dimensions.

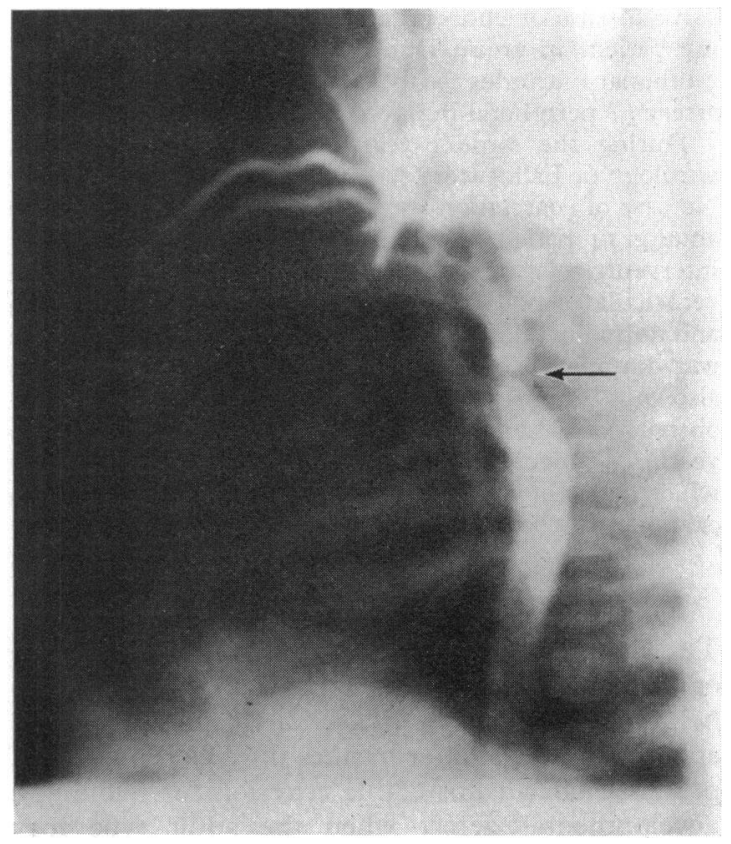

FIG. 3 Aortogram to demonstrate juxtaductal coarctation. The indentation on the posterior aspect of the aorta is clearly seen $(\leftarrow)$ opposite the ductus.

abnormal isthmal narrowing which may or may not be associated with juxtaductal coarctation. In the analysis presented here, all patients with d-transposition of the great vessels and ventricular septal defect or common ventricle with d- or l-transposition but without pulmonary stenosis (group C) were found to have the principal aortic obstruction at the isthmus. Fig. 4 demonstrates the anatomy in a patient with d-transposition of the great vessels and ventricular septal defect, a condition commonly presenting in the first few weeks of life. Angiocardiography performed at that time commonly shows the pulmonary artery to be increased and the ascending aorta to be decreased in size. A possible explanation is that in the fetus most of the venous return to the heart was conducted to the pulmonary artery rather than to the aorta resulting in the disproportionately small size of the ascending aorta.

If flow to the ascending aorta is reduced, for example by 50 per cent, then only 25 per cent of the combined fetal ventricular output traverses the aorta (Fig. 5). If the innominate, left common carotid, and left subclavian vessels draw their normal 20 to 25 per cent of the combined fetal ventricular output, flow through the isthmus will be less than 5 per cent. Hence the expected and often profound isthmal narrowing. 


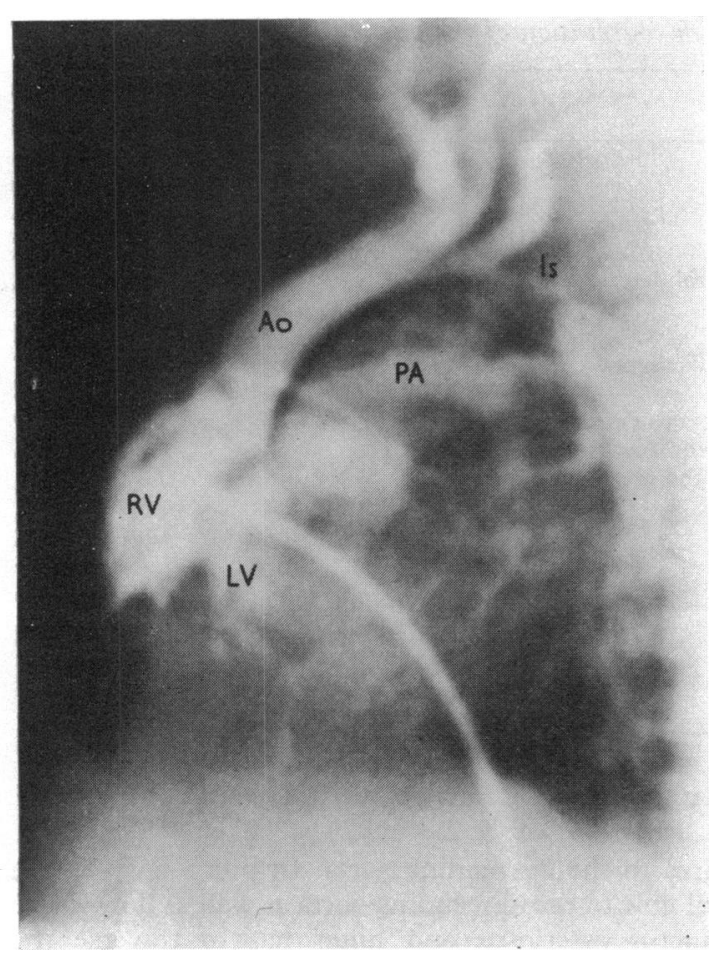

FIG. 4 Angiogram demonstrating right ventricle $(R V)$, left ventricle $(L V)$, aorta $(A o)$, and pulmonary artery $(P A)$ in a patient with $d$-transposition of the great arteries and ventricular septal defect. The $P A$ is larger than the anterior aorta which has extreme narrowing at the isthmus (Is).

Why should aortic flow in the fetus with dtransposition of the great arteries and ventricular septal defect be reduced? One explanation is that the fetal pulmonary artery will be receiving inferior vena caval rather than superior vena caval blood. In the normal fetus the inferior vena caval blood, which includes the umbilical (placental) venous return, $\mathrm{Po}_{2}$ approximately $30 \mathrm{mmHg}$ (Meschia et al., 1965), passes through the foramen ovale to left atrium, left ventricle, and aorta, whereas the pulmonary artery receives predominantly superior vena caval return $\left(\mathrm{Po}_{2} 20 \mathrm{mmHg}\right)$. In d-transposition the pulmonary artery arises from the left ventricle and hence is perfused with blood, the $\mathrm{Po}_{2}$ of which is approximately $10 \mathrm{mmHg}$ higher than in the normal. The higher fetal pulmonary artery $\mathrm{PO}_{2}$ in dtransposition and ventricular septal defect may result in less pulmonary vasoconstriction and hence more flow to the lungs, with corresponding diversion of blood away from the aorta.

Another factor tending to divert flow from aorta
NEONATAL AORTA IN D-TGA + VSD

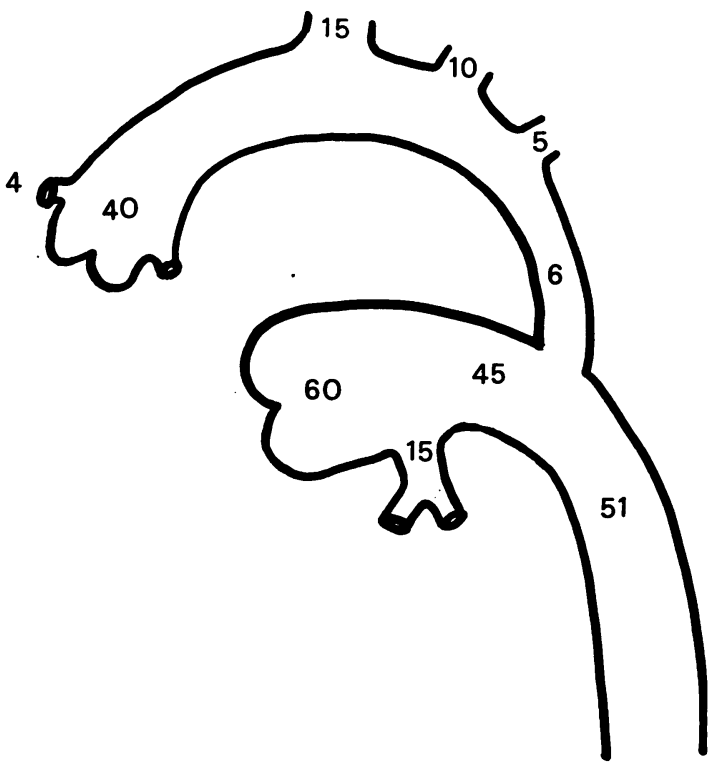

FIG. 5 Diagram to show the expected proportion of the combined fetal ventricular output that passes to aorta and pulmonary artery in a patient with $d-$ transposition of the great arteries and a ventricular septal defect.

to pulmonary artery in d-transposition and ventricular septal defect is the origin of the aorta from an infundibulum. The subaortic muscular conus may act as a partial obstruction tending to divert flow away from the aorta (Van Praagh et al., 1971). However, pressure gradients across the right ventricular outflow tract were not demonstrated.

Although the basis for abnormal isthmal narrowing remains conjecture, it does explain the association with the more complex cardiac anomalies in group C.

\section{Physiological disturbance in patients with co- arctation and associated intracardiac anom- alies}

In the series presented here (Table) 83 of 162 patients (groups B and C) had an intracardiac abnormality where the dominant physiological disturbance was a left-to-right shunt and the pulmonary: systemic flow ratio was $>I$.

Of the 18 patients in group $D$, all but one had abnormalities of the left side of the heart, namely mitral stenosis or incompetence, aortic stenosis, or endocardial fibroelastosis of the left ventricle. One 
TABLE Additional cardiac anomalies in patients with coarctation of the aorta

\begin{tabular}{|c|c|c|c|c|}
\hline & & Total & $M$ & $F$ \\
\hline Group A & Isolated & 6r & 46 & I5 \\
\hline \multirow{6}{*}{ Group B } & Persistent ductus arteriosus & 20 & II & 9 \\
\hline & Ventricular septal defect & 12 & 8 & 4 \\
\hline & Persistent ductus arteriosus + ventricular septal defect & 16 & 5 & II \\
\hline & Atrial septal defect & 7 & 4 & 3 \\
\hline & AV canal & 4 & $\mathbf{2}$ & 2 \\
\hline & 1-transposition of the great arteries + ventricular septal defect & 2 & 2 & o \\
\hline \multirow{6}{*}{ Group C } & d-transposition + ventricular septal defect \pm persistent ductus arteriosus & 8 & 6 & 2 \\
\hline & d-transposition of the great arteries + persistent ductus arteriosus & 2 & 2 & 0 \\
\hline & Common ventricle $+\mathrm{d}-$ or 1 -transposition of the great arteries & 8 & 4 & 4 \\
\hline & Total anomalous pulmonary venous drainage & 2 & I & I \\
\hline & Double outlet right ventricle & I & $\mathbf{I}$ & o \\
\hline & Mitral atresia + ventricular septal defect & $\mathbf{I}$ & $\mathbf{I}$ & ० \\
\hline \multirow{4}{*}{ Group D } & Mitral valve disease & 8 & 4 & 4 \\
\hline & Aortic valve disease & 4 & 3 & $\mathbf{I}$ \\
\hline & Endocardial fibroelastosis & 5 & 2 & 3 \\
\hline & Peripheral pulmonary stenosis & I & $\mathbf{I}$ & o \\
\hline & Total & 162 & 103 & 59 \\
\hline
\end{tabular}

patient has peripheral pulmonary stenosis where the pressure difference at cardiac catheterization was distal to the ductus arteriosus. The proportion of patients with aortic valve disease $(2.5 \%)$ was lower than in some other series. However, we excluded bicuspid aortic valve with no measureable pressure difference between left ventricle and aorta since angiographically the diagnosis may not be certain. In none of our patients with coarctation was there a dominant right-to-left shunt with decreased pulmonary blood flow. Furthermore, no patients had right ventricular outflow tract obstruction.

Whether or not the haemodynamic explanations presented for the two types of coarctation are valid (Rudolph et al., 1972), our findings show that diminution of pulmonary flow or right ventricular outflow tract obstruction appears to protect against development of coarctation.

The explanation offered for this lack of association of coarctation with right ventricular outflow tract obstruction or dominant right-to-left shunts is based on postulated flow patterns in the fetus. Fig. 6 shows the theoretical fetal flow patterns in pulmonary atresia. As no blood is ejected from the right ventricle directly to the pulmonary artery, Ioo per cent of the combined fetal ventricular output leaves the heart via the ascending aorta which is a proportionally larger structure than normal (Fig. 7).

As successive vessels arise from the aortic arch, so aortic dimensions decrease but the aortic isthmus will have a greater or at least similar cross-sectional area to the descending aorta. In pulmonary atresia all flow to the descending aorta as well as flow to the ductus arteriosus and lungs has to traverse the isthmus which, if dimensions of vessels are deter-

NEONATAL AORTA IN PULMONARY ATRESIA

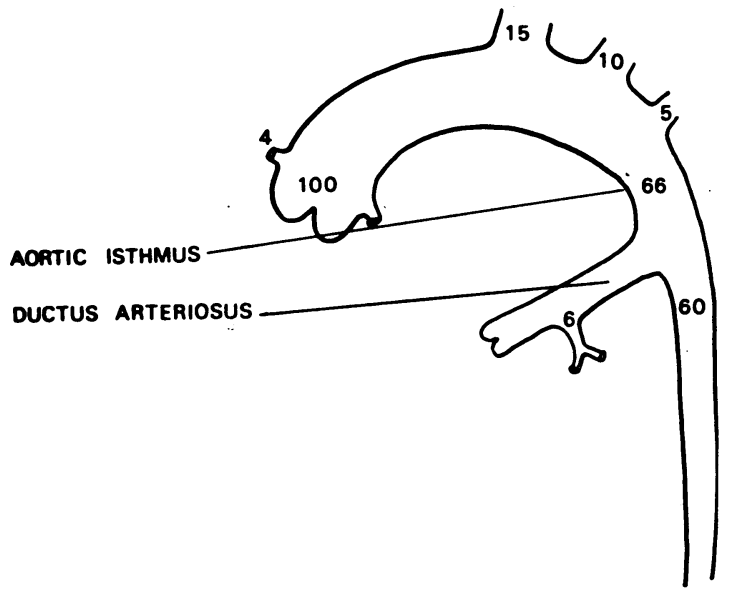

FIG. 6 Diagram to show the expected proportion of the combined fetal ventricular output that passes to aorta and pulmonary artery in a patient with pulmonary atresia. 


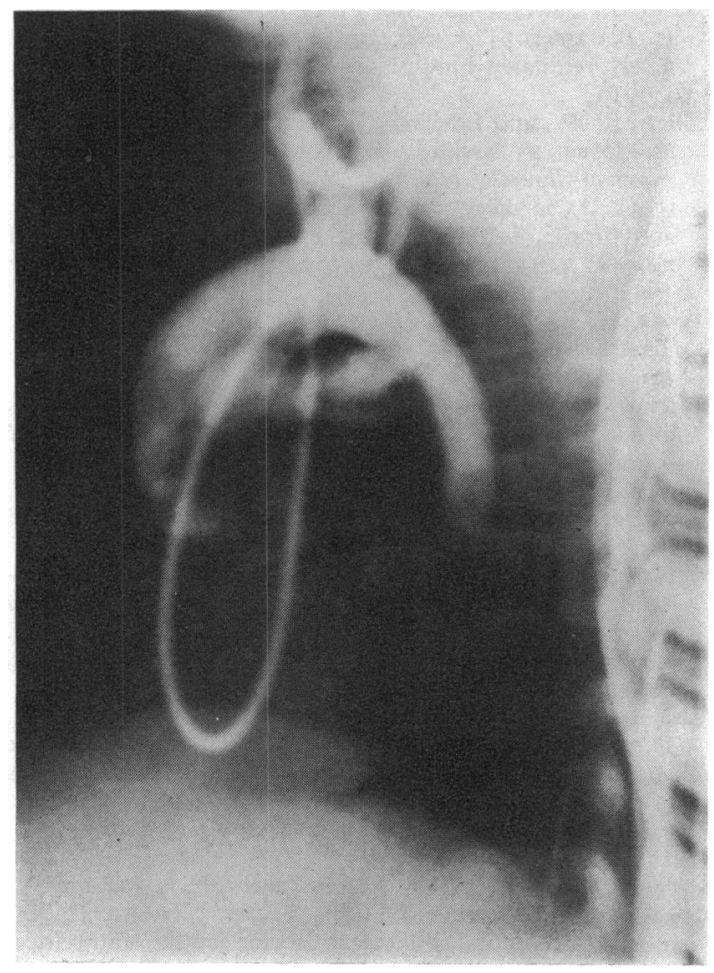

FIG. 7 Aortogram in patient with pulmonary atresia (aged I day). The isthmus is wider than the descending aorta and the ductus arteriosus makes an abnormal angle with the aorta.

mined by flow through them, must be wider than the descending aorta. In all congenital cardiac anomalies where there is a dominant right-to-left shunt at birth with oligaemic lung fields, i.e. pulmonary atresia \pm ventricular septal defect, tetralogy of Fallot with infundibular stenosis, tricuspid atresia with normally related great vessels (but not with transposed great vessels), the aortic isthmus will be wider than the descending aorta. When this is so, coarctation caused by a narrowed isthmus will not be expected. Furthermore, as there is no disparity in size between isthmus and descending aorta, no indentation on the posterior aortic wall is present, and hence juxtaductal coarctation also is not seen. This contrasts strongly with any of the left-to-right shunt situations in groups $B$ or $C$ where diversion of blood away from the aorta will tend to exaggerate disparity in size between isthmus and descending aorta. The fetal flow pattern also explains the abnormal angle at which the duct arises from the ascending aorta in pulmonary atresia (Rudolph et al., 1972; Miller et al., 1973) (Fig. 7).
NEONATAL AORTA IN TETRALOGY OF FALLOT

MODERATE RV OUTFLOW TRACT OBSTRUCTION

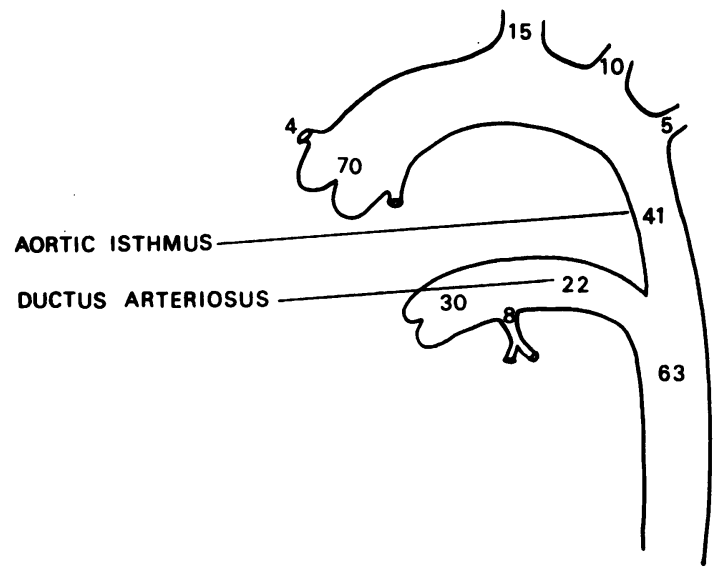

FIG. 8 Diagram to show the expected proportion of the combined fetal ventricular output that passes to the aorta and the pulmonary artery in a patient with tetralogy of Fallot with moderate right ventricular outflow tract obstruction.

\section{Fetal flow patterns in tetralogy of Fallot}

In tetralogy of Fallot the degree of right ventricular outflow tract obstruction at birth varies, and patients may present with signs of a ventricular septal defect and left-to-right shunt. Most, however, have some degree of outflow tract obstruction and the hypothetical flow pattern in a patient with mild infundibular stenosis is shown in Fig. 8. Again, flow is diverted from the pulmonary artery to aorta and though the isthmus may not be as wide as the descending aorta, major disparity in size between them is not found.

\section{Truncus arteriosus}

Similar considerations apply in truncus arteriosus (Collett and Edwards, 1949) which also is not found in association with coarctation. Isthmal narrowing is absent in the fetus as all flow reaching the descending aorta will have traversed the isthmus and therefore normal neonatal isthmal narrowing is absent.

\section{Fetal flow patterns in group $D$ patients}

In the majority of patients in group $D$ there was an abnormality of the mitral valve, or left ventricular 
myocardium. By raising the left atrial pressure, mitral stenosis would be expected to deter inferior vena caval return from passing through the foramen ovale, thus reducing left ventricular stroke output and ascending aortic flow. A raised left ventricular end-diastolic pressure from an endocardial fibroelastosis or aortic valve disease would have a similar effect by raising left atrial pressure. Mitral incompetence may also reduce forward flow from the left ventricle which together with a raised left atrial pressure again diverts blood from the ascending aorta. Even a minor reduction in aortic flow relative to pulmonary flow might accentuate the isthmus-descending aorta difference in size, and hence the indentation on the posterior aortic wall. Conversely any impedance to pulmonary flow from tricuspid or pulmonary stenosis will divert superior vena caval return or a higher proportion of inferior vena caval return to the left atrium so increasing ascending aortic flow, decreasing pulmonary and ductal flow, and reducing the size disparity between isthmus and descending aorta.

In a study of necropsy material, Hutchins (I97I) found 60 per cent of cases with severe aortic valve obstruction to have coarctation, whereas no patients dying from pulmonary obstruction had coarctation. Only one patient in our series had a right-sided obstructive lesion, namely mild peripheral pulmonary stenosis. This was of insufficient severity to have altered fetal flow patterns. As flow to the lungs is less than 8 per cent of the combined fetal ventricular output, severe peripheral pulmonary stenosis, provided it were distal to the ductus, would have a negligible effect on fetal haemodynamics.

In conclusion, strong circumstantial evidence has been presented in support of a haemodynamic pathogenesis of coarctation. In addition, an explanation based on fetal flow patterns has been advanced to account for the hitherto poorly understood prevalence or absence of certain intracardiac anomalies with coarctation.

Our thanks are due to the physicians and surgeons at the Brompton Hospital for access to patients' notes and to Miss Elizabeth Thompson for the art work.

The concepts in this paper developed during tenure by E.A.S. of a British Heart Foundation - American Heart Association Travelling Fellowship at the Cardiovascular Research Institute, University of California, San Francisco.

\section{References}

Becker, A. E., Becker, M. J., and Edwards, J. E. (1970). Anomalies associated with coarctation of aorta. Particular reference to infancy. Circulation, 4r, 1067.
Cassin, S., Dawes, G. S., Mott, J. C., Ross, B. B., and Strang, L. B. (1964). The vascular resistance of the foetal and newly ventilated lung of the lamb. Fournal of Physiology, I7I, 6r.

Collett, R. W., and Edwards, J. E. (1949). Persistent truncus arteriosus: a classification according to anatomic types. Surgical Clinics of North America, 29, 1245.

Cook, C. D., Drinker, P. A., Jacobson, H. N., Levison, M., and Strang, L. B. (1963). Control of pulmonary blood flow in the foetal and newly born lamb. Fournal of Physiology, 169, I0.

Dawes, G. S., Mott, J. G., and Widdicombe, J. G. (1954). The foetal circulation in the lamb. Fournal of Physiology, 126, 563.

Hutchins, G. M. (1971). Coarctation of the aorta explained as a branch-point of the ductus arteriosus. American fournal of Pathology, 63, 203.

Lauer, R. M., Evans, J. A., Aoki, H., and Kittle, C. F. (1965). Factors controlling pulmonary vascular resistance in fetal lambs. Fournal of Pediatrics, 67, 568.

McNamara, D. G. (1971). Coarctation - course and prognosis in infancy and childhood. In The Natural History and Progress - in Treatment of Congenital Heart Defects, p. 267. Ed. by S. L. Kidd and J. D. Keith. Charles C. Thomas, Springfield, Illinois.

Meschia, G., Cotter, J. R., Breathnach, C. S., and Barron, D. H. (I965). The hemoglobin, oxygen, carbon dioxide and hydrogen ion concentrations in the umbilical bloods of sheep and goats as sampled via indwelling plastic catheters. Quarterly fournal of Experimental Physiology, 50, 185 .

Miller, G. A. H., Restifo, M., Shinebourne, E. A., Paneth, M., Joseph, M. C., Lennox, S. C., and Kerr, I. H. (1973). Pulmonary atresia with intact ventricular septum and critical pulmonary stenosis presenting in first month of life. Investigation and surgical results. British Heart fournal, 35, 9.

Patten, B. M. (1930). The changes in circulation following birth. American Heart fournal, 6, 192.

Rudolph, A. M., and Heymann, M. A. (1967). The circulation of the fetus in utero: methods for studying distribution of blood flow, cardiac output and organ blood flow. Circulation Research, 21, 163.

Rudolph, A. M., Heymann, M. A., and Spitznas, U. (1972). Hemodynamic considerations in the development of narrowing of the aorta. American fournal of Cardiology, 30, 514 .

Rudolph, A. M., Heymann, M. A., Teramo, K. A. W., Barrett, C. T., and Raiha, N. C. R. (197I). Studies on the circulation of the previable human fetus. Pediatric $R e-$ search, 5, 452 .

Shinebourne, E. A. (1974). Growth and development of the cardiovascular system: functional development. In Scientific Foundations of Paediatrics, p. 198. Heinemann, London.

Sinha, S. N., Kardatzke, M. L., Cole, R. B., Muster, A. J., Wessel, H. U., and Paul, M. H. (1969). Coarctation of the aorta in infancy. Circulation, 40, 385 .

Tawes, R. L., Jr., Aberdeen, E., Waterston, D. J., and Bonham-Carter, R. E. (1969). Coarctation of the aorta in infants and children. A review of 333 operative cases, including 179 infants. Circulation, 39, Suppl. I, 173.

Van Praagh, R., Bernhard, W. F., Rosenthal, A., Parisi, L. F., and Fyler, D. C. (197I). Interrupted aortic arch: surgical treatment. American fournal of Cardiology, 27, 200.

Requests for reprints to Dr. Elliot A. Shinebourne, Department of Paediatrics, Brompton Hospital, Fulham Road, London $\mathrm{SW}_{3} 6 \mathrm{HP}$. 